\title{
Pre-flight evaluation of adult patients with cystic fibrosis: a cross-sectional study
}

\author{
Elisabeth Edvardsen ${ }^{1,4^{*}} \mathbb{D}$, Aina Akerø ${ }^{1}$, Ole Henning Skjønsberg ${ }^{1,2}$ and Bjørn Skrede ${ }^{1,3}$
}

\begin{abstract}
Background: Air travel may imply a health hazard for patients with cystic fibrosis (CF) due to hypobaric environment in the aircraft cabin. The objective was to identify pre-flight variables, which might predict severe hypoxaemia in adult CF patients during air travel.

Methods: Thirty adult CF-patients underwent pre-flight evaluation with spirometry, arterial oxygen tension $\left(\mathrm{PaO}_{2}\right)$, pulse oximetry $\left(\mathrm{SpO}_{2}\right)$ and cardiopulmonary exercise testing (CPET) at sea level (SL). The results were related to the $\mathrm{PaO}_{2}$ obtained during a hypoxia-altitude simulation test (HAST) in which a cabin altitude of $2438 \mathrm{~m}$ (8000 ft) was simulated by breathing $15.1 \%$ oxygen.
\end{abstract}

Results: Four patients fulfilled the criteria for supplemental oxygen during air travel $\left(\mathrm{PaO}_{2}\right.$ HAST $\left.<6.6 \mathrm{kPa}\right)$. While walking slowly during HAST, another eleven patients dropped below $\mathrm{PaO}_{2}$ HAST $6.6 \mathrm{kPa}$. Variables obtained during CPET $\left(\mathrm{PaO}_{2 \text { CPET }}, \mathrm{SPO}_{2 \text { CPET, }}\right.$ minute ventilation/carbon dioxide output, maximal oxygen uptake) showed the strongest correlation to $\mathrm{PaO}_{2 \text { HAST }}$.

Conclusions: Exercise testing might be of value for predicting in-flight hypoxaemia and thus the need for supplemental oxygen during air travel in CF patients.

Trial registration The study is retrospectively listed in the ClinicalTrials.gov Protocol Registration System: NCT01569880 (date; 30/3/2012)

Keywords: Blood gas response, Cardiopulmonary exercise testing, Gas exchange, Hypoxia altitude simulation test, Pulmonary function

\section{Background}

Due to medical improvement and preventive initiatives, both quality of life and the longevity of patients with cystic fibrosis (CF) have increased substantially during the past 10-20 years. Today, CF-patients participate in all aspects of modern life, including air travelling. However, due to the hypobaric environment in the aircraft cabin, air travel may imply a health hazard for CF-patients, most of them suffering from chronic pulmonary disease. The ambient oxygen partial pressure inside the aircraft cabin during commercial air travel is reduced, corresponding to an altitude of $2438 \mathrm{~m}(8000 \mathrm{ft})$ at maximal

\footnotetext{
${ }^{*}$ Correspondence: elisabeth.edvardsen@nih.no

1 Department of Pulmonary Medicine, Oslo University Hospital, Ullevål, Oslo, Norway

Full list of author information is available at the end of the article
}

cruising altitude [1]. CF-patients are therefore prone to a substantial reduction in the partial arterial oxygen pressure $\left(\mathrm{PaO}_{2}\right)$ during the flight.

Guidelines concerning pre-flight evaluation of patients with pulmonary disease have suggested various screening variables as normative, such as oxygen saturation at sea level and spirometric values [2-4]. In case of doubt, a hypoxia-altitude simulation test (HAST) has been recommended as decisive. HAST is performed by breathing a gas mixture containing $15.1 \%$ oxygen corresponding to an altitude of 2438 metres [5]. Administration of supplemental oxygen during flight is advised if $\mathrm{PaO}_{2}$ drops below $6.6 \mathrm{kPa}$ during the test $[3,4]$.

Several studies addressing pre-flight evaluation of lung patients have been published, mainly on patients with chronic obstructive pulmonary disease (COPD) [6-11]. However, these results may not be applicable to 
the CF-population. CF-patients are generally younger, have fewer additional (cardiovascular) risk factors, and the pathophysiology causing hypoxaemia may differ from that of COPD [12]. The literature regarding in-flight hypoxaemia in patients with CF is limited [13-18], and reliable screening methods for predicting development of severe in-flight hypoxaemia in CF patients have not been identified [3]. In COPD patients, it has been claimed that pre-flight measurement of arterial blood gases $\left(\mathrm{PaO}_{2}\right)$ is the single most helpful test for predicting in-flight $\mathrm{PaO}_{2}$ in lung patients [19]. In previous reports on CF patients, however, arterial blood gas measurements have, to our knowledge, not been performed. In addition, recent studies have advocated that exercise testing is of value for predicting which patients will develop in-flight hypoxaemia $[20,21]$, but this aspect is also lacking in studies on CF-patients.

Given the widespread use of air travelling in adult patients with CF [16], further knowledge is needed to identify pre-flight variables which might predict in-flight hypoxaemia. The aims of the present study were to investigate the relationship between hypoxaemia achieved during HAST $\left(\mathrm{PaO}_{2}\right.$ HAST $)$ and sea level values of pulmonary function, arterial blood gases, pulse oximetry and cardiopulmonary exercise test (CPET) variables. In addition, the effect of slow walking during hypoxic exposure, simulating slow walking along the aircraft's aisle, was studied.

\section{Methods}

From January 2006 to December 2008, all adult CF patients referred to the National Center for Cystic Fibrosis at Oslo University Hospital, Norway for comprehensive assessment, and who were in a stable phase of their disease, were invited to participate in this cross-sectional HAST study. Criteria for eligibility were $>16$ years of age and sputum test negative for Burkholderia cepacia and/ or methicillin resistant Staphylococcus aureus.

The CF diagnosis was confirmed both genetically and clinically. The Regional Committee for Medical Ethics (Oslo, Norway) approved the study, and written informed consents were obtained by all participants. The study is retrospectively listed in the ClinicalTrials.gov Protocol Registration System (NCT01569880).

\section{Pre-flight tests}

Pre-flight tests were obtained at sea level ( $30 \mathrm{~m}$ above sea level, hereafter referred to as sea level) while breathing ambient air. Lung function tests were performed using Vmax Series, (VIASYS, Yorba Linda, USA) [22]. After $5 \mathrm{~min}$ at rest in the sitting position, the percutaneous oxygen saturation $\left(\mathrm{SpO}_{2} \mathrm{SL}\right)$ was measured with a finger probe using a stationary pulse oximeter (NONIN 8600,
Medical, Inc., Minneapolis, USA), and arterial blood gas samples were drawn from a radial artery cannula. The samples were immediately analysed (ABL 700 series, Radiometer, Copenhagen, Denmark).

CPET was performed by walking and running on a treadmill (Jaeger LE 100, Würzburg, Germany) until exhaustion, using a progressive $1 \mathrm{~min}$ step protocol. Gas exchanges and ventilatory variables were continuously sampled breath by breath through a Hans Rudolph two way breathing mask (Hans Rudolph Inc, Kansas City, USA). The breathing mask was connected to a Vmax SensorMedics metabolic analyzer (Yorba Linda, California, USA) to assess ventilatory variables and the content of oxygen and carbon dioxide of expired air for calculation of oxygen uptake $\left(\mathrm{VO}_{2}\right) . \mathrm{VO}_{2 \max }$ was accepted when $\mathrm{VO}_{2}$ failed to raise despite rise in speed and ventilation $\left(\mathrm{V}_{\mathrm{E}}\right)$ or strong signs of exhaustion. Ventilation/perfusion mismatch was confirmed by impairment of ventilatory efficiency measured as elevated $\mathrm{V}_{\mathrm{E}} / \mathrm{VCO}_{2}$ ratio at the anaerobic threshold calculated by the ventilatory equivalent method [23]. Arterial blood gases were sampled just before ending the exercise test.

\section{Simulated flight}

HAST was performed while the participants were breathing a hypoxic gas mixture of $15.1 \%$ oxygen balanced with nitrogen via a non-diffusion gas collection bag (Hans Rudolph Inc., Kansas City, USA) in the sitting position for $15 \mathrm{~min}$ [5]. The bag was connected to a tight fitting mask with a two way non-breathing valve (Hans Rudolph Inc., Kansas City, USA). Subsequently, the participants walked on the treadmill at $1.2 \mathrm{~km} \cdot$ hour $^{-1}$ for 5 min corresponding to walking along the aisle, still breathing the hypoxic gas.

Arterial blood gases were obtained from a radial artery catheter at sea level every fifth minute during the hypoxic exposure and at the end of the 5 min' walk. If the percutaneous oxygen saturation $\left(\mathrm{SpO}_{2 \text { HAST }}\right)$ dropped $\leq 85 \%$ an extra arterial blood sample was taken. All samples were analysed immediately as previously described. The $\mathrm{SpO}_{2}$ HAST was measured continuously with a finger probe (NONIN 8600, Medical, Inc., Minneapolis, USA). A 12-lead ECG monitoring (Cardiosoft, GE Marquette Medical Systems, Milwaukee, USA) was conducted throughout the test for evaluation of ischemia or arrhythmias. Dyspnoea was scored by the BORG CR10-scale [24].

\section{Statistical analysis}

Demographic data are presented as mean values \pm standard derivation (SD) unless otherwise specified. No missing values were imputed in the study. Differences between sea level values and HAST values were analysed 
using Student's paired $T$ test. Correlation between forced expiratory volume after $1 \mathrm{~s}\left(\mathrm{FEV}_{1}\right), \mathrm{PaO}_{2 \mathrm{SL}}, \mathrm{SpO}_{2} \mathrm{sL}$ and CPET variables at sea level and $\mathrm{PaO}_{2}$ HAST were assessed by Pearson's correlation coefficient (r) with 95\% confidence intervals (CI). Statistical significance level was set to $5 \%$.

\section{Results}

Thirty-two patients (male $=21$ ) were enrolled in the study to perform a HAST. Of these, 14 patients also performed a CPET. Two CF patients were excluded, one due to an on-going infection and one due to discomfort related to the artery catheter. The reason for declining to participate in the study was primarily due to refusal to accept arterial cannulation.

\section{Pre-flight values}

Table 1 shows the patient demographics, spirometric values, resting sea level blood gas values, variables during $\mathrm{CPET}$, and blood gas values during HAST. Fifteen patients (50\%) had a $\mathrm{FEV}_{1}<50 \%$ of predicted, 16 patients $(53 \%)$ had a $\mathrm{SpO}_{2 \mathrm{SL}}<95 \%$, and six patients (20\%) had a $\mathrm{PaO}_{2}$ $\mathrm{SL}<9.3 \mathrm{kPa}$, cut-off values which have all been suggested as criteria for supplemental oxygen during air travel [3].
The average $\mathrm{VO}_{2 \max }$ during CPET $(\mathrm{n}=14)$, was $36.1 \pm 10.5 \mathrm{ml} \cdot \mathrm{kg}^{-1} \cdot \mathrm{min}^{-1}$, which was $88 \%$ of predicted. Four patients $(29 \%)$ had a $\mathrm{V}_{\mathrm{E}} / \mathrm{VCO}_{2}$ ratio $>35$, indicating ventilation/perfusion mismatching.

\section{Hypoxia altitude simulation test}

In all patients, the $\mathrm{PaO}_{2}$ was considerably lower during HAST than at sea level $(7.43 \pm 0.89$ vs $10.18 \pm 1.19 \mathrm{kPa}$; $\mathrm{p}<0.001)$. Four patients $(13 \%)$ fulfilled the criteria for supplemental oxygen during air travel based on the BTS recommendations $\left(\mathrm{PaO}_{2}<6.6 \mathrm{kPa}\right)$ [3]. Of these, all had $\mathrm{FEV}_{1}<50 \%$ of predicted, three had $\mathrm{SpO}_{2 \mathrm{SL}}<95 \%$, and two had a $\mathrm{PaO}_{2 \mathrm{SL}}<9.3 \mathrm{kPa}$.

The average $\mathrm{PaO}_{2}$ HAST during slow walking on the treadmill was $6.91 \pm 0.87 \mathrm{kPa}$ vs $7.55 \pm 0.84(\mathrm{p}<0.001)$ at rest $(\mathrm{n}=27)$, adding another eleven patients to the group of subjects dropping below $6.6 \mathrm{kPa}$. Seven of these patients (23\%) had $\mathrm{FEV}_{1}<50 \%$, five (17\%) had $\mathrm{SpO}_{2}$ $\mathrm{sL}<95 \%$, and two patients $(7 \%)$ had a $\mathrm{PaO}_{2 \mathrm{SL}}<9.3 \mathrm{kPa}$.

No cardiac arrhythmias or signs of ischemia were observed during HAST. One patient reported moderate and two reported weak dyspnoea on the BORG CR10 scale. However, none of these patients fulfilled the criteria for supplemental oxygen during air travel.

Table 1 Descriptive data of the participants, pulmonary function, blood gas variables and exercise variables, reported as mean (SD)

$\begin{array}{lr}\text { Age and anthropometry }(\mathrm{n}=30) & \\ \text { Age }(\mathrm{yrs}) & 34.2(11.81) \\ \text { Body mass }(\mathrm{kg}) & 67.7(16.35) \\ \text { Height }(\mathrm{cm}) & 174.4(9.31) \\ \text { BMI }\left(\mathrm{kg} / \mathrm{m}^{2}\right) & 21.9(3.65) \\ \text { Pulmonary function } & \\ \text { FEV }_{1}(\mathrm{~L}) & 2.25(1.12) \\ \text { FEV }_{1}(\% \text { predicted }) & 58.6(24.8) \\ \text { FVC }(\mathrm{L}) & 3.60(1.22) \\ \text { FVC }(\% \text { of predicted }) & 79.4(20.9) \\ \text { FEV }_{1} / \mathrm{FVC} \text { ratio } & 60.5(12.3)\end{array}$

\begin{tabular}{|c|c|c|c|c|}
\hline & Sea level & Exercise $(n=14)$ & HAST & HAST slow $(n=20)$ walking \\
\hline \multicolumn{5}{|l|}{ Blood gas variables } \\
\hline $\mathrm{SpO}_{2}(\%)$ & $94.8(2.2)$ & $88.6(8.2)$ & $88.6(4.1)$ & $87.0(3.8)$ \\
\hline $\mathrm{SaO}_{2}(\%)$ & $95.4(1.5)$ & $90.1(8.4)$ & $89.1(2.8)$ & $86.3(3.8)$ \\
\hline $\mathrm{PaO}_{2}(\mathrm{kPa})$ & $10.2(1.2)$ & $9.8(2.0)$ & $7.4(0.9)$ & $6.9(0.9)$ \\
\hline $\mathrm{PaCO}_{2}(\mathrm{kPa})$ & $5.0(0.4)$ & - & $5.0(0.3)$ & $5.0(0.3)$ \\
\hline Symptoms (BORG 10 CR) & $0.09(0.23)$ & - & $0.5(0.8)$ & $0.9(1.1)$ \\
\hline \multicolumn{5}{|l|}{ CPET variables } \\
\hline $\mathrm{VE} / \mathrm{NCO}_{2}$ & & $33.0(4.9)$ & & \\
\hline $\mathrm{VO}_{2 \max }\left(\mathrm{ml} \cdot \mathrm{kg}^{-1} \cdot \mathrm{min}^{-1}\right)$ & & $36.1(10.5)$ & & \\
\hline $\mathrm{VO}_{2 \max }(\%$ predicted $)$ & & $87.5(23.6)$ & & \\
\hline $\mathrm{HR}_{\max }\left(\right.$ beat $\left.\cdot \mathrm{min}^{-1}\right)$ & & $175(14.1)$ & & \\
\hline
\end{tabular}

$B M I$ body mass index, $F E V_{1}$ forced expiratory volume in one second, $F V C$ forced vital capacity, $\mathrm{SpO}_{2}$ saturation for oxygen measured by pulse oximetry, $\mathrm{VO}_{2 \max }$ maximal oxygen uptake, $H R_{\max }$ maximal heart rate during CPET 


\section{Correlation between pre-flight- and HAST variables}

Figure 1 shows the correlation between $\mathrm{PaO}_{2}$ HAST and pre-flight values. There was a moderate correlation between $\mathrm{PaO}_{2}$ HAST and $\mathrm{FEV}_{1}, \mathrm{PaO}_{2}$ SL and $\mathrm{SaO}_{2}$ SL, while no significant correlation between $\mathrm{PaO}_{2}$ HAST and $\mathrm{SpO}_{2}$ SL was observed. Data from the CPET (Fig. 2) showed a strong correlation between $\mathrm{PaO}_{2}$ HAST and $\mathrm{PaO}_{2}$ CPET, $\mathrm{SpO}_{2}$ CPET, $\mathrm{VE} / \mathrm{VCO}_{2}$ CPET and $\mathrm{SaO}_{2}$ CPET . In addition, a moderate correlation was observed between $\mathrm{PaO}_{2}$ HAST and $\mathrm{VO}_{2 \max }$.

\section{Discussion}

So far, no studies have demonstrated a simple and reliable method for identifying which CF-patients will become severely hypoxemic during air travel. In the present study, $30 \mathrm{CF}$ patients were examined during a standardized hypoxia altitude simulation test. Four out of 30 patients dropped to a $\mathrm{PaO}_{2}<6.6 \mathrm{kPa}$ during HAST, thereby fulfilling an internationally accepted criterion for supplemental oxygen during air travel $[3,4]$. In addition, 11 patients dropped below $\mathrm{PaO}_{2}<6.6 \mathrm{kPa}$ during slow walking on the treadmill while breathing the hypoxic gas mixture, underlining the impact of even very light physical activity during hypoxic conditions. $\mathrm{PaO}_{2}$ HAST was modestly correlated to sea level $\mathrm{FEV}_{1}, \mathrm{PaO}_{2}$ and, $\mathrm{SaO}_{2}$ at rest. However, a strong correlation was observed between $\mathrm{PaO}_{2}$ HAST and variables obtained during maximal exercise, i.e. $\mathrm{PaO}_{2 \text { CPET }}, \mathrm{SpO}_{2}$ CPET and $\mathrm{VO}_{2 \text { max }}$, and a strong negative correlation was observed between $\mathrm{PaO}_{2}$ HAST and the $\mathrm{V}_{\mathrm{E}} /$ $\mathrm{VCO}_{2}$ ratio.

A methodological limitation of the study was that only 14 of the 30 patients performed a CPET. However, a post hoc power calculation for a correlation coefficient of 0.7 revealed that 13 participants were sufficient for detecting a significant difference from zero with $80 \%$ power.

\section{Pre-flight variables at rest}

The usefulness of $\mathrm{FEV}_{1}$ in the pre-flight assessment has been debated. In a study of 69 adult CF patients, Peckham et al. found that $\mathrm{FEV}_{1}$ was significantly correlated
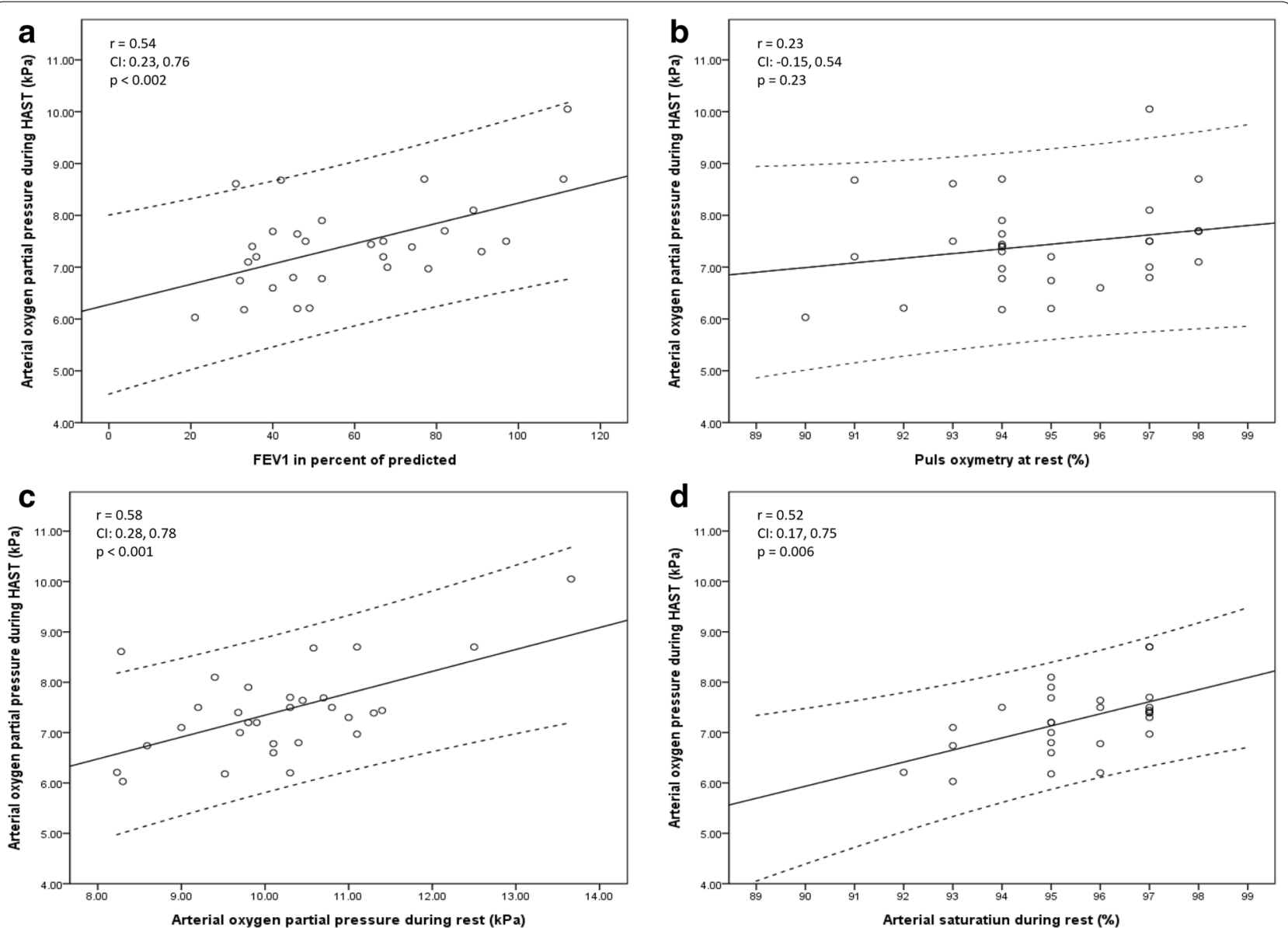

Fig. 1 Relationships between arterial oxygen partial pressure $\left(\mathrm{PaO}_{2}\right)$ during Hypoxia Altitude Simulation Test (HAST) and forced expiratory volume in one second $\left(\mathrm{FEV}_{1}\right)(\mathbf{a})$, pulse oximetry $\left(\mathrm{SpO}_{2}\right)(\mathbf{b}), \mathrm{PaO}_{2}(\mathbf{c})$ and $\mathrm{SaO}_{2}$ at rest $(\mathbf{d})$ 

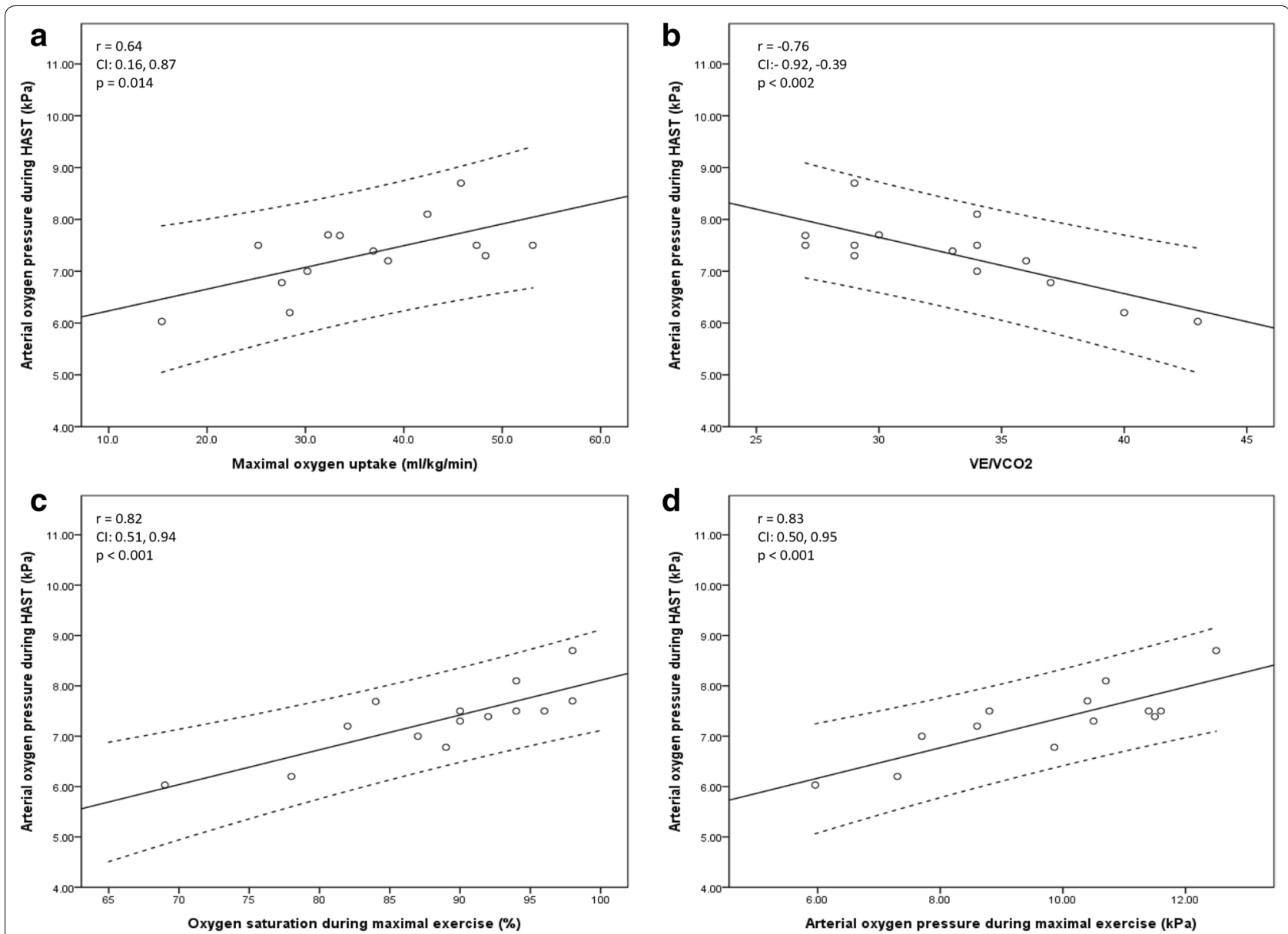

Fig. 2 Relationships between arterial oxygen partial pressure $\left(\mathrm{PaO}_{2}\right)$ during Hypoxia Altitude Simulation Test (HAST) and physiological variables during exercise; maximal oxygen uptake (a), ventilatory eqvivalent for carbon dioxide ratio $\left(\mathrm{VE} / \mathrm{VCO}_{2}\right)(\mathbf{b})$, pulse oximetry $\left(\mathrm{SpO}_{2}\right)(\mathbf{c})$ and $\mathrm{PaO} 2(\mathbf{d})$

to $\mathrm{PaO}_{2 \text { HAST }}[18]$. In a study of 87 children with CF who travelled by air, Buchdahl et al. concluded that $\mathrm{FEV}_{1}$ was a better predictor of in-flight desaturation than HAST [25]. The results of the present study confirm a modest correlation between $\mathrm{PaO}_{2}$ HAST and $\mathrm{FEV}_{1}$. The four CF-patients who fulfilled the criteria for supplemental oxygen all had a $\mathrm{FEV}_{1}$ below $50 \%$ of predicted, which is in agreement with other studies investigating adult CFpatients $[17,18]$. It is, however, worth noting that 11 patients with a $\mathrm{FEV}_{1}<50 \%$ predicted in the present study had a negative HAST $\left(\mathrm{PaO}_{2} \geq 6.6 \mathrm{kPa}\right)$. With regard to COPD patients, $\mathrm{FEV}_{1}$ has proven to be a poor predictor of in-flight hypoxaemia $[10,11]$. The revised BTS recommendations regarding air travel state a poor relationship between $\mathrm{FEV}_{1}$ and hypoxaemia in passengers with pulmonary disease in general [3]. According to the literature, $\mathrm{FEV}_{1}$ seems to be a somewhat better predictor of in-flight hypoxaemia in CF patients than in patients with COPD, but both the present and previous studies are too small to draw reliable conclusions of whether CF patients with a $\mathrm{FEV}_{1}>50 \%$ predicted can travel safely by air without supplementary oxygen.

Symptoms during HAST were in general mild in most patients, but increased slightly during slow walking. Only one of the patients that fulfilled the criteria for supplemental oxygen reported symptoms (weak), indicating that HAST was well tolerated in those who became very hypoxic.

Pulse oximetry is easy to perform and available at most medical centres. However, the latest BTS recommendations (2011) state that sea level $\mathrm{SpO}_{2}$ does not predict hypoxaemia as accurately as previously assumed [3]. This is in line with the current study showing that there was no significant correlation between pre-flight $\mathrm{SpO}_{2}$ and $\mathrm{PaO}_{2}$ HAST. One of the patients with a resting pulse oximetry $\geq$ 95\% fulfilled the criteria for supplementary oxygen in the present study. Similar observations have been presented in a study on COPD patients [11]. Thus, a $\mathrm{SpO}_{2} \geq 95 \%$ does not seem to be a reliable cut off value for travelling safely without supplemental oxygen. In a recently published 
study, an algorithm employing a combination of pulse oximetry at rest and during a 6 min walking test was used for pre-flight screening of COPD patients. It was found that this combination was a reliable tool for discriminating between COPD patients who can travel without supplementary oxygen, those who need such treatment, and the group of patients who needs more advanced pre-flight testing with HAST [26]. This algorithm has not been evaluated in relation to patients with CF.

In medical guidelines for air travel, it has been claimed that a stable pre-flight $\mathrm{PaO}_{2}$ exceeding $9.3 \mathrm{kPa}$ is sufficient for travelling by air without supplemental oxygen $[2,5]$. This has been contradicted by several studies on COPD patients $[10,11]$. In the current study, two patients who required supplemental oxygen according to the HAST had a pre-flight $\mathrm{PaO}_{2}$ above $9.3 \mathrm{kPa}(9.5$ and $10.3 \mathrm{kPa}$ ). Hence, using pre-flight $\mathrm{PaO}_{2}>9.3 \mathrm{kPa}$ as a criterion for acceptable $\mathrm{PaO}_{2}$ levels during air travel in patients with CF does not exclude in-flight hypoxaemia.

\section{Pre-flight variables during exercise}

The current study shows that $\mathrm{PaO}_{2}$ and $\mathrm{SpO}_{2}$ during maximal exercise are strongly correlated with $\mathrm{PaO}_{2}$ HAST . Also, the pre-flight $\mathrm{VO}_{2 \max }$ showed a stronger correlation to $\mathrm{PaO}_{2 \mathrm{HAST}}$ than $\mathrm{FEV}_{1}, \mathrm{SpO}_{2}$ and $\mathrm{PaO}_{2}$ measured at rest. These findings are in agreement with previous findings in COPD patients during both hypobaric chamber exposure at $2438 \mathrm{~m}$ and during a commercial flight [10, 11, 27], showing that pre-flight aerobic capacity and exercise desaturation were strongly correlated with the in-flight $\mathrm{PaO}_{2}$. Since exercise testing is a part of the annual assessment at most $\mathrm{CF}$-centres, exercise desaturation may be a good indicator for need of supplemental oxygen during air travel, also for CF patients with severe lung disease. In general, CPET is shown to be well tolerated in severely ill patients [28-30].

The ventilatory efficiency defined by ventilation relative to $\mathrm{CO}_{2}$-production $\left(\mathrm{V}_{\mathrm{E}} / \mathrm{VCO}_{2}\right)$ ratio [23] has not previously been studied as a variable in relation to development of in-flight hypoxaemia in patients with lung disease. In CF patients, hypoxaemia is mainly related to a mismatch between ventilation and perfusion in the lung caused by the chronic inflammation and mucus plugging [31], and an elevated $\mathrm{V}_{\mathrm{E}} / \mathrm{VCO}_{2}$ ratio measured at the anaerobic threshold indicates an uneven distribution of ventilation and perfusion [23]. The $\mathrm{V}_{\mathrm{E}} / \mathrm{VCO}_{2}$ ratio is highly reproducible, and the degree of elevation has been shown to reflect the severity of ventilation-perfusion mismatching [29]. The pre-flight $\mathrm{V}_{\mathrm{E}} / \mathrm{VCO}_{2}$ ratio in the present study showed a strong negative correlation to $\mathrm{PaO}_{2}$ HAST. The two patients with the highest $\mathrm{V}_{\mathrm{E}} / \mathrm{VCO}_{2}$ ratio both fulfilled the criteria for supplemental oxygen, and those patients who had a moderate elevation of $\mathrm{V}_{\mathrm{E}} / \mathrm{VCO}_{2}$ ratio had a moderate reduction in $\mathrm{PaO}_{2 \mathrm{HAST}}$. It should be noted that the $\mathrm{V}_{\mathrm{E}} / \mathrm{VCO}_{2}$ ratio can also be elevated during hyperventilation due to anxiety or discomfort wearing a tight mask. However, no objective (high respiratory exchange ratio) or subjective sign of hyperventilation was observed during the test.

Taken together, these results indicate that exercise testing might be of value in the pre-flight assessment of lung patients, including patients with CF.

\section{Hypoxia altitude simulation test}

HAST has proven to be a practical and reliable method for advanced pre-flight evaluation of patients with lung disease [32], and is today considered to be the 'gold standard' in clinical practise $[26,33]$. In the present study, HAST has been used as the reference method for detecting development of hypoxaemia under hypoxic conditions. It should be noted, however, that Buchdahl et al. observed a poor relationship between $\mathrm{SpO}_{2}$ obtained during HAST and during a real flight [25]. This could be due to the fact that $\mathrm{SpO}_{2}$ seems to be inferior to $\mathrm{PaO}_{2}$ as a tool for predicting development of in-flight hypoxaemia [34]. As shown in other groups of lung patients, even light exercise seems to aggravate hypoxaemia under hypoxic conditions $[10,26]$. This might be of importance for patients during long haul flights where the passengers are encouraged to exercise and also are in need of visiting the lavatory. Thus, in the authors' opinion, light exercise should preferably be included in the HAST protocol. Other hazards than hypoxaemia during air travel may in general be the risk of venous thromboembolism due to immobilisation [35]. This condition may easily be prevented by use of compression stocking in combination with doing calf-muscle exercise. In-flight transmission of infectious disease is also a risk for CF patients [36].

\section{Conclusions}

In summary, we have studied the relationship between the development of hypoxaemia during a simulated flight and regularly used tests of pulmonary function, blood gases and gas exchange variables during exercise in a group of adult patients with CF. Furthermore, the effect of slow walking during HAST was studied showing a pronounced aggravation of the hypoxaemia.

Variables obtained during CPET showed a stronger correlation to in-flight hypoxaemia than spirometric values and blood gas values obtained at rest. This is in accordance with studies on COPD patients. Thus, future studies should probably concentrate on establishing reliable cut off values during CPET, making them suitable for use in pre-flight screening of patients with CF. 


\section{Abbreviations}

BTS: British thoracic society; CF: cystic fibrosis; Cl: confidence interval; COPD: chronic obstructive pulmonary disease; CPET: cardiopulmonary exercise test; $\mathrm{FEV}_{1}$ : forced expiratory volume after one second; HAST: hypoxia-altitude simulation test; $\mathrm{SL}$ : sea level; $\mathrm{SpO}_{2}$ : pulse oximetry; $\mathrm{PaO}_{2}$ : arterial oxygen tension; $\mathrm{V}_{\mathrm{E}}$ : minute ventilation; $\mathrm{VO}_{2}$ : oxygen uptake; $\mathrm{VO}_{2 \text { max }}$ : maximal oxygen uptake.

\section{Authors' contributions}

$E E$, the guarantor of the study and responsible for the accuracy of the data, contributed to the conception and design of the study, collected and analysed the data, and drafted the manuscript. OHS participated in the design of the study. AA collected and analysed the data. BS participated in the design of the study and collected data. All authors contributed to the interpretation of data. All authors read and approved the final manuscript.

\section{Author details}

${ }^{1}$ Department of Pulmonary Medicine, Oslo University Hospital, Ullevål, Oslo, Norway. ${ }^{2}$ Faculty of Medicine, University of Oslo, Oslo, Norway. ${ }^{3}$ National Center for Cystic Fibrosis, Oslo University Hospital, Oslo, Norway. ${ }^{4}$ Department of Sports Medicine, Norwegian School of Sport Sciences, Oslo, Norway.

\section{Acknowledgements}

The authors gratefully acknowledge the kind co-operation of participants in this study. We also thank Jorunn Homme for excellent work regarding recruitment of the participants.

\section{Competing interests}

The author declares that they have no competing interests.

\section{Availability of data and materials}

The datasets analysed during the current study are not publically available due to restrictions made by the investigating institution but are available from the corresponding author on reasonable request.

\section{Consent to publish}

A written consent for publication of data was obtained from all participants.

\section{Ethics approval and consent to participate}

The Regional Committee for Medical Ethics (Oslo, Norway) approved the study, and written informed consents were obtained by all participants before entering the study.

Received: 3 October 2015 Accepted: 13 January 2017

Published online: 06 February 2017

\section{References}

1. Cottrell JJ. Altitude exposures during aircraft flight. Flying higher. Chest. 1988:93:81-4

2. Medical guidelines for air travel. Aerospace Medical Association, Air Transport Medicine Committee, Alexandria, Va. Aviat Space Environ Med. 1996:67:B1-16.

3. Ahmedzai S, Balfour-Lynn IM, BewickT, Buchdahl R, Coker RK, Cummin AR, et al. Managing passengers with stable respiratory disease planning air travel: British Thoracic Society recommendations. Thorax. 2011;66(Suppl 1):i1-30.

4. British Thoracic Society Standards of Care Committee. Managing passengers with respiratory disease planning air travel: British Thoracic Society recommendations. Thorax. 2002;57:289-304.

5. Gong H Jr, Tashkin DP, Lee EY, Simmons MS. Hypoxia-altitude simulation test. Evaluation of patients with chronic airway obstruction. Am Rev Respir Dis. 1984;130:980-6.

6. Schwartz JS, Bencowitz HZ, Moser KM. Air travel hypoxemia with chronic obstructive pulmonary disease. Ann Intern Med. 1984;100:473-7.

7. Seccombe LM, Kelly PT, Wong CK, Rogers PG, Lim S, Peters MJ. Effect of simulated commercial flight on oxygenation in patients with interstitial lung disease and chronic obstructive pulmonary disease. Thorax. 2004;59:966-70.
8. Kelly PT, Swanney MP, Seccombe LM, Frampton C, Peters MJ, Beckert L. Air travel hypoxemia vs. the hypoxia inhalation test in passengers with COPD. Chest. 2008;133:920-6.

9. Dillard TA, Berg BW, Rajagopal KR, Dooley JW, Mehm WJ. Hypoxemia during air travel in patients with chronic obstructive pulmonary disease. Ann Intern Med. 1989;111:362-7.

10. Christensen CC, Ryg M, Refvem OK, Skjonsberg OH. Development of severe hypoxaemia in chronic obstructive pulmonary disease patients at 2438 m (8000 ft) altitude. Eur Respir J. 2000;15:635-9.

11. Akero A, Christensen CC, Edvardsen A, Skjonsberg OH. Hypoxaemia in chronic obstructive pulmonary disease patients during a commercial flight. Eur Respir J. 2005;25:725-30.

12. Kruhlak RT, Jones RL, Brown NE. Regional air trapping before and after exercise in young adults with cystic fibrosis. West J Med. 1986;145:196-9.

13. Rose DM, Fleck B, Thews O, Kamin WE. Blood gas-analyses in patients with cystic fibrosis to estimate hypoxemia during exposure to high altitudes in a hypobaric-chamber. Eur J Med Res. 2000;5:9-12.

14. Martin SE, Bradley JM, Buick JB, Bradbury I, Elborn JS. Flight assessment in patients with respiratory disease: hypoxic challenge testing vs. predictive equations. QJM. 2007;100:361-7.

15. Kamin W, Fleck B, Rose DM, Thews O, Thielen W. Predicting hypoxia in cystic fibrosis patients during exposure to high altitudes. J Cyst Fibros. 2006;5:223-8.

16. Fischer R, Lang SM, Bruckner K, Hoyer HX, Meyer S, Griese M, et al. Lung function in adults with cystic fibrosis at altitude: impact on air travel. Eur Respir J. 2005;25:718-24.

17. Thews O, Fleck B, Kamin WE, Rose DM. Respiratory function and blood gas variables in cystic fibrosis patients during reduced environmental pressure. Eur J Appl Physiol. 2004;92:493-7.

18. Peckham D, Watson A, Pollard K, Etherington C, Conway SP. Predictors of desaturation during formal hypoxic challenge in adult patients with cystic fibrosis. J Cyst Fibros. 2002;1:281-6.

19. Aerospace Medical Association. Medical guidelines for airline travel. 2nd ed. Aviat Space Environ Med. 2003;74:A1-19.

20. Edvardsen A, Akero A, Hardie JA, Ryg M, Eagan TM, Skjonsberg OH, et al High prevalence of respiratory symptoms during air travel in patients with COPD. Respir Med. 2011;105:50-6.

21. Chetta A, Castagnetti C, Aiello M, Sergio F, Fabiano N, Tzani P, et al. Walking capacity and fitness to fly in patients with chronic respiratory disease. Aviat Space Environ Med. 2007:78:789-92.

22. Laszlo G. European standards for lung function testing: 1993 update. Thorax. 1993:48:873-6.

23. Sun XG, Hansen JE, Garatachea N, Storer TW, Wasserman K. Ventilatory efficiency during exercise in healthy subjects. Am J Respir Crit Care Med. 2002;166:1443-8

24. Borg GA. Perceived exertion. Exerc Sport Sci Rev. 1974;2:131-53.

25. Buchdahl RM, Babiker A, Bush A, Cramer D. Predicting hypoxaemia during flights in children with cystic fibrosis. Thorax. 2001;56:877-9.

26. Edvardsen A, Akero A, Christensen CC, Ryg M, Skjonsberg OH. Air travel and chronic obstructive pulmonary disease: a new algorithm for preflight evaluation. Thorax. 2012;67(11):964-9.

27. Akerø A, Edvardsen A, Ryg M, Skjønsberg $\mathrm{OH} . \mathrm{PaO}_{2}$ During Exercise As a Predictor for in-Flight Hypoxemia in COPD Patients (abstr). European Respiratory Society (ERS) Annual Congress; 2008

28. Jones LW, Eves ND, Haykowsky M, Joy AA, Douglas PS. Cardiorespiratory exercise testing in clinical oncology research: systematic review and practice recommendations. Lancet Oncol. 2008;9:757-65.

29. Palange P, Ward SA, Carlsen KH, Casaburi R, Gallagher CG, Gosselink R, et al. Recommendations on the use of exercise testing in clinical practice. Eur Respir J. 2007:29:185-209.

30. Ross RM. ATS/ACCP statement on cardiopulmonary exercise testing. Am J Respir Crit Care Med. 2003;167:1451.

31. Dantzker DR, Patten GA, Bower JS. Gas exchange at rest and during exercise in adults with cystic fibrosis. Am Rev Respir Dis. 1982;125:400-5.

32. Akero A, Edvardsen A, Christensen CC, Owe JO, Ryg M, Skjonsberg OH. COPD and air travel: oxygen equipment and preflight titration of supplemental oxygen. Chest. 2011;140:84-90.

33. Johnson AO. Chronic obstructive pulmonary disease * 11 : fitness to fly with COPD. Thorax. 2003;58:729-32. 
34. Akero A, Christensen CC, Edvardsen A, Ryg M, Skjonsberg OH. Pulse oximetry in the preflight evaluation of patients with chronic obstructive pulmonary disease. Aviat Space Environ Med. 2008;79:518-24.

35. Silverman $D$, Gendreau M. Medical issues associated with commercial flights. Lancet. 2009;373:2067-77.
36. Mangili A, Gendreau MA. Transmission of infectious diseases during commercial air travel. Lancet. 2005;365:989-96.
Submit your next manuscript to BioMed Central and we will help you at every step:

- We accept pre-submission inquiries

- Our selector tool helps you to find the most relevant journal

- We provide round the clock customer support

- Convenient online submission

- Thorough peer review

- Inclusion in PubMed and all major indexing services

- Maximum visibility for your research

Submit your manuscript at www.biomedcentral.com/submit
() Biomed Central 